\title{
Changes of the Endothelium and Extracellular Matrix in Thoracic Aortic Aneurysm Revealed by Scanning Electron Microscopic Investigations Are there Structural Parallels to Aortic Valve Degeneration?
}

\author{
Mirzaie Masoud $^{1 *}$, Michael Schultz ${ }^{2}$, Peter Schwartz ${ }^{2}$, Zaur Guliyev ${ }^{1}$ and Sheila Fatehpur ${ }^{1}$ \\ ${ }^{1}$ Department of Vascular Surgery, Lippe-Lemgo Hospital, University clinics OWL, Germany \\ ${ }^{2}$ Institute for Anatomy, University of Göttingen, Göttingen, Germany
}

*Corresponding author: Masoud Mirzaie, Head of the Department of Vascular Surgery University Hospital of Lemgo, Germany

\begin{abstract}
Objective: Thoracic aneurysms occur most frequently with $60 \%$ in ascending aorta and arch, und in $40 \%$ the descending aorta, although the etiological factors are different for individual segments. While, depending on localization, factors such as atherosclerosis, bicuspid aortic valve, familial thoracic aortic aneurysm syndrome, Turner syndrome, Marfan syndrome, aortic arteritis in Takayasu's arteritis, trauma and dissection lead to the formation of thoracic aortic aneurysms, the structural changes of the basement membrane and the exact causes of the mechanism of thoracic aortic aneurysm are not known. The aim of this study was to investigate the pathophysiological origin of thoracic aortic aneurysms from a morphological point of view.
\end{abstract}

Patients and methods: For this study, between 2007 and 2017,12 patients with thoracic aortic aneurysms with contraindications to interventional therapy underwent open surgery. All patients underwent multi- detector row CT with three-dimensional (3D) reformation in $3 \mathrm{~mm}$ slices and transesophageal echocardiography, Tissue samples were taken from descending aorta of two female (average age, 72.32 years) and 10 male patients (63.12 years), and were fixed for 6 hours in a solution containing $2.5 \%$ glutaraldehyde and $0.2 \mathrm{mMol}$ cacodylate. The samples were finally visualized using the digital scanning microscope.

Results: In addition to partial desquamation of the endothelium, severe alterations of the collagen fibers and basal membrane and repair attempts in the form of endothelial islets and deep tears in the fibers, cancellation and destruction of the helical structure of collagen fibers are visible.

Conclusion: In summary, in thoracic aortic aneurysms we found severe structural changes of collagen fibres, endothelium and basement membrane, which occur in a similar form in acquired aortic valve degeneration.

Keywords: Thoracic aortic aneurysm, electron microscopy,

\section{Introduction}

Thoracic aortic aneurysms (TAAs) are potentially devastating, and due to their asymptomatic behavior, pose a serious health risk characterized by the lack of medical treatment options and high rates of surgical morbidity and mortality [1,2]. Independent of the inciting stimuli (biochemical/mechanical), TAA development proceeds by a multifactorial process influenced by both cellular and

extracellular mechanisms, resulting in alterations of the structure and composition of the vascular extracellular matrix (ECM) $[3,4]$. The molecular mechanisms leading to ascending thoracic aortic aneurysms (ATAAs) remain unknown. Diseases affecting the ascending aorta, such as these thoracic aortic aneurysms and type I and II dissections, are primarily associated with medial necrosis, which is characterized by fragmentation and loss of elastic fibers, 
loss of muscle cells and interstitial collections of collagenous fibers and basophilic ground substance [5,6]. The aim of this study was the evaluation of the changes of endocardium and extracellular matrix in thoracic aortic aneurysms.

\section{Materials and methods Tissue samples}

Table 1: Baseline characteristics of the study population.

\begin{tabular}{|c|c|c|}
\hline \multirow{2}{*}{ Age } & Male & Female \\
\cline { 2 - 3 } & 10 & 2 \\
\cline { 2 - 3 } & $(63.12$ years $)$ & $(72.32$ years $)$ \\
\hline \multirow{3}{*}{ Comorbidities } \\
\hline Nicotin, active & $4(40.0 \%)$ & $1(50 \%)$ \\
\hline Ex-nicotin & $1(10.0 \%)$ & 0 \\
\hline Hypertension & $8(80.0 \%)$ & $1(50 \%)$ \\
\hline Diabetes & $4(40 \%)$ & $1(50 \%)$ \\
\hline Hyperlipoproteinemia & $4(40.0 \%)$ & 0 \\
\hline Hyperuricaemia & $1(10.0 \%)$ & 0 \\
\hline CHD & $3(30.0 \%)$ & 0 \\
\hline Carcinoma & $1(10.0 \%)$ & 0 \\
\hline Renal insufficiency & $2(20.0 \%)$ & 0 \\
\hline COPD, emphysema & $2(20.0 \%)$ & $1(50 \%)$ \\
\hline
\end{tabular}

Continous variables are presented as an absolute percentage. Abbreviations: CHD: Coronar Heart Disease, COPD: Chronic obstructive pulmonary disease
Tissue samples were taken from the descending aorta of two female (average age, 72.32 years) and 10 male patients (63.12 years). 8 patients were undergoing emergency surgical resection and four patients elective resection. Preoperative diagnostics and therapy were performed according to the guidelines of the European Society of Cardiology for the diagnosis and therapy of aortic aneurysms. Thus, all patients underwent preoperative thoracic CT angiography with three- dimensional (3D) reformation in $3 \mathrm{~mm}$ slices and transesophageal echocardiography. The indication for surgery was set for an aneurysm size of $>5.5 \mathrm{~cm}$, for smaller aneurysms the indication was given only in the presence of grade 3 aortic valve insufficiency, and as an emergency in the case of perforation [7]. Table 1 presents summarized data of the basic patient characteristics.

\section{Scanning Electron Microscopy}

In order to reveal the morphology of the tissue sample, scanning electron microscopy was performed in all tissue samples. Specimens from the descending aortic were fixed for 6 hours in a solution containing $2.5 \%$ glutaraldehyde and $0.2 \mathrm{mMol}$ cacodylate. Afterwards, samples were dehydrated in a series of increasing concentrations of alcohol. After critical point drying, all samples were sputtered with gold-palladium. Samples were visualized using the digital scanning microscope (Zeiss DSM 960, Germany).

\section{Results}

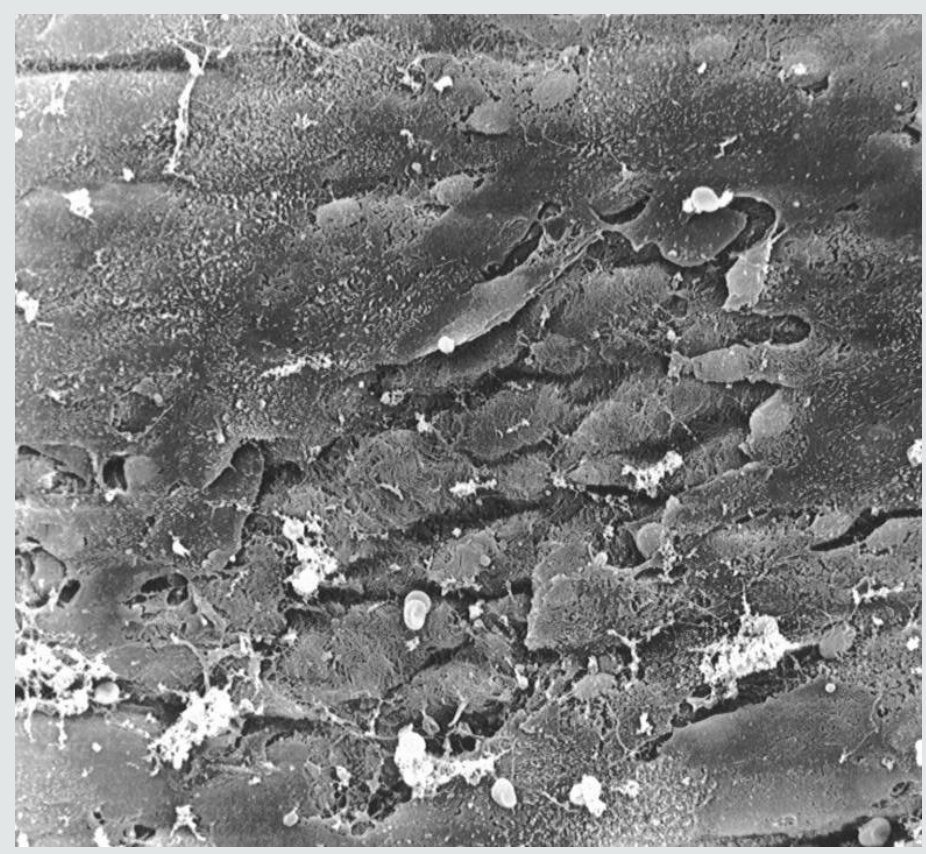

Figure 1: Electronmikroscopical view of inner aortic wall, 1000 x magnification: desquamation of endothelial cells from basal membrane with partially dissolved cell junctions and destruction of collagen fibers. 
Scanning electron microscopical findings. In all samples we studied the endothelial tissue materials which are, for the most part, desquamated. The intervening tissue, collagen and elastic fibers are destroyed, and are infiltrated mainly with red cells. Rarely, are the collagen fibers present in the island form obtained endothelial cells. At higher magnification, deep tears in the fibers, cancellation and destruction of the helical structure of collagen fibers are visible. The remaining endothelial cells are swollen. The intercellular junction is partially disrupted, and only available in a few fibers. The collagen fibers are partially hypertrophied. In such places, the endothelial cells are deposited in the fibers, the lamina elastic interna is for the most part no longer exists (Figures 1, 2). The endothelial cells are present as islands. The surface of the endothelial cells are transformed villi, reminiscent of endothelial cells of the duodenum (Figures 3,4). The deep defects of the extracellular matrix are covered in places by the normal endothelium as a partial reendothelialisation and give the impression of a deep crater (Figure 5).

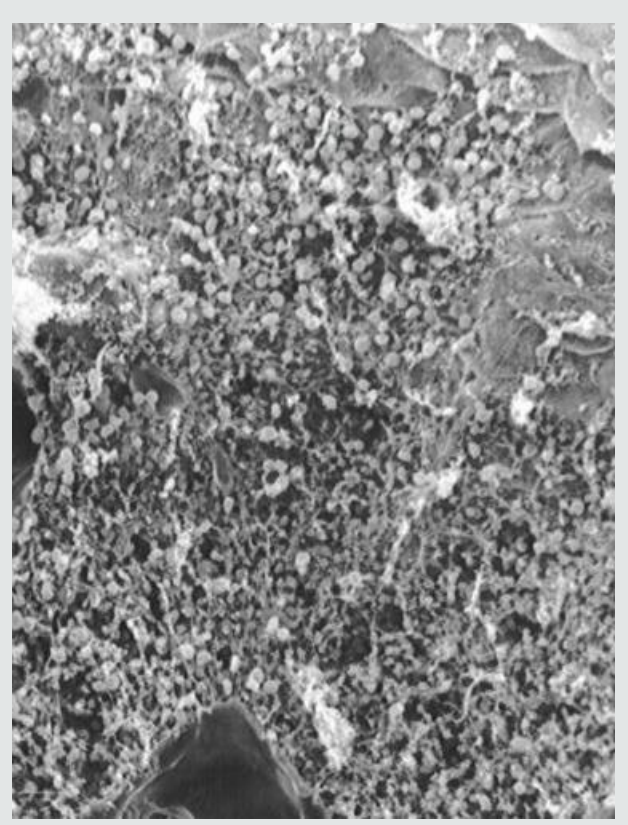

Figure 2: Electronmikroscopical view of inner aortic wall, $1500 \times$ magnification, destruction of collagen and elastic fibers with infiltration mainly by red cells, the collagen fibers rarely are present in the island form obtained endothelial cells.

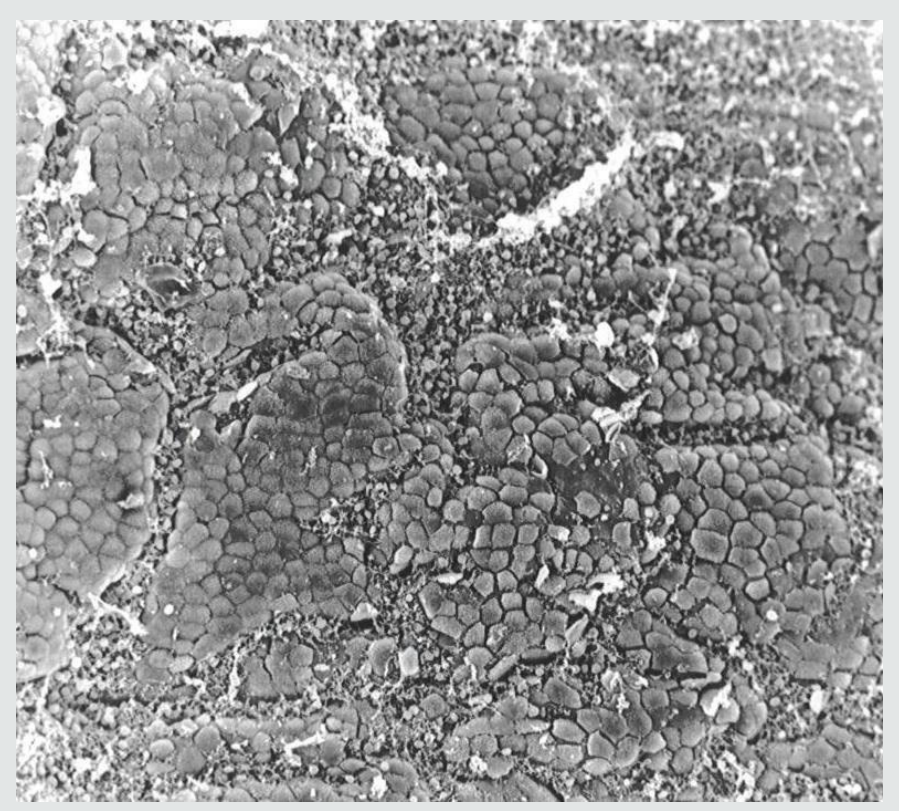

Figure 3: Electron microscopical view of cell island of aortic wall, $1000 \mathrm{x}$ magnification, the endothelial cells are present as islands. 


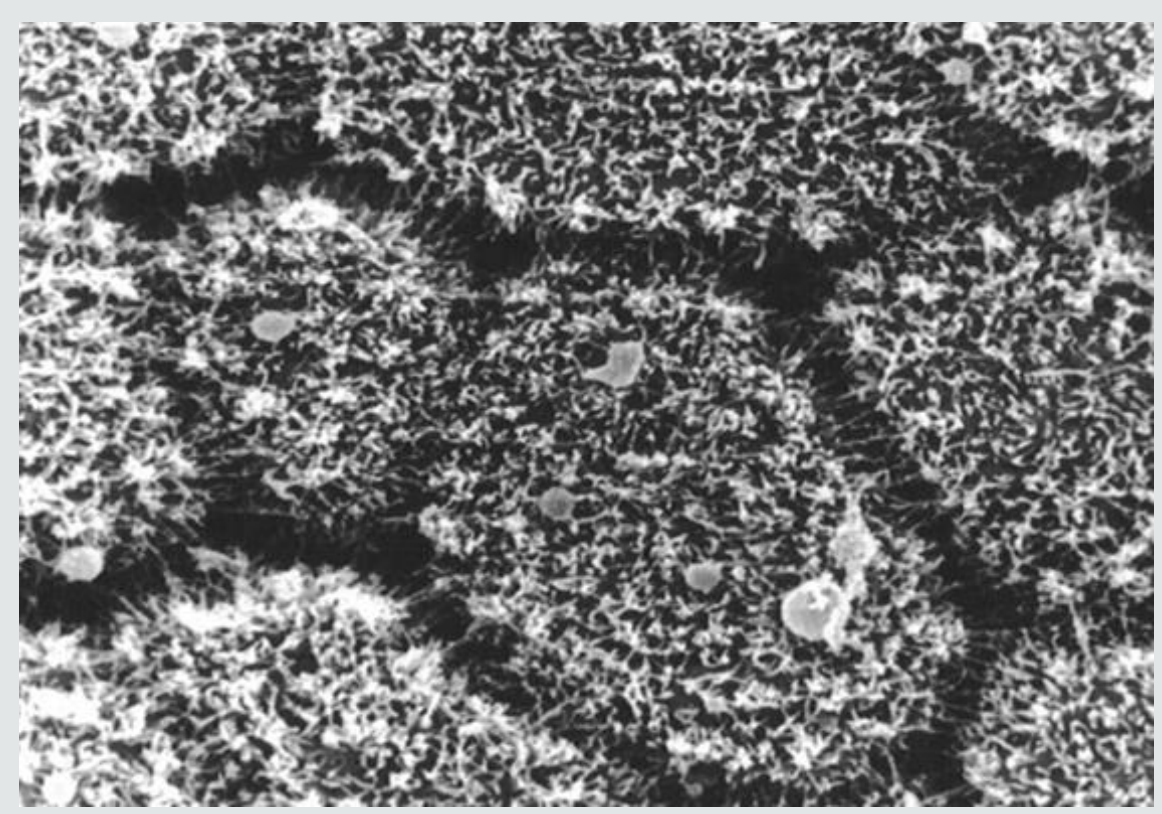

Figure 4: Electron micro scopical view of cell island of aortic wall, 2000 x magnification, the surface of the endothelial cells are transformed into villi, reminiscent to endothelial cells of the duodenum.

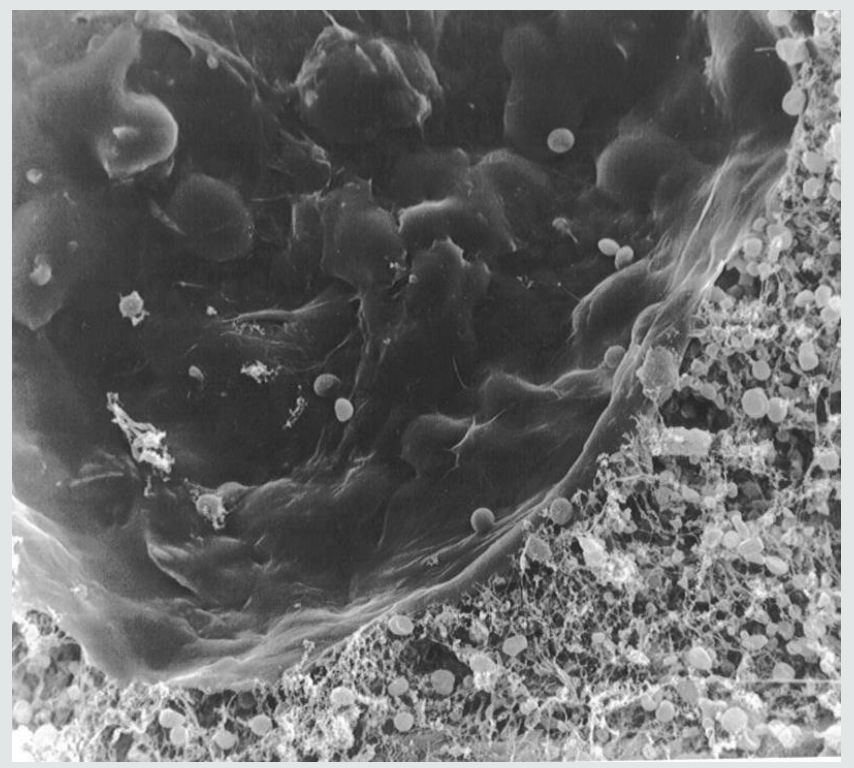

Figure 5: Electronmicroscopical view of inner aortic wall, $2500 \times$ magnification, the deep defects of the extracellular matrix are in places covered by the endothelium, which lokks irregular. The shape of endothelial coating shows very deep defects in aortic wall.

\section{Discussion}

Thoracic aortic aneurysms and dissections constitue a critical condition that often goes undiagnosed with fatal consequences. Besides, various inherited forms discussed, genetic factors are discussed, genetic factors being important in the development of thoracic aneurysms [8,9]. Familial aortic aneurysm (FAA) has been described in such conditions as the Marfan and Ehlers- Danols syndrome type IV, which are due to defects in the fibrillin-1 and
III procollagen genes respectively [10-14]. In this group of a novel locus at chromosome 11q23.3-q24 was detected, a critical step toward elucidating a gene defect responsible for aortic dilatation [15]. Hasham et al. Determined one locus, mapped to 5q13-14, which will enhance the chances to determine persons at risk for aortic aneurysm in non-familial aortic aneurysm diseases [5]. Thoracic aortic aneurysms and infrarenal aortic aneurysms exhibit distinct patterns of gene expression relative to the normal aorta from the same sites [14]. Keramat mapped in familial TAA, a single 
locus on chromosome 15q21 with the peak lod score of 6.3 at the fibrillin-1 gene [16]. The molecular changes of the extracellular matrix have been the subject of many studies. In this study, we have investigated the morphological structural changes of the endothelium and the extracellular matrix in aneurysmal changes in the descending aorta. The endothelial cells were desquamated, for the most part, the remaining once grouped into smaller islands. These showed a transformation to villi-like structures on their surface, which showed morphological similarities with to cells of the duodenum. These changes are associated with different pathophysiological dysfunction of the endothelium. The Nogo-B is highly expressed in endothelial cells following downregulated induction by lysophosphatidylcholine,

which contributed to atherossclerotic lesions [17]. In TAA, the Nogo-B mRNA and protein expression are downregulated, which correlate to the formation of aneurysm [10]. The ageassociated changes in endothelial nitric oxide synthase expression have not been definitively linked to pathophysiology of aortic aneurysm [18]. As a sign of endothelial inflammatory response the increased VCAM-1 expression has been detected in human aorta with atheromatous changes [19]. In descending thoracic aortic anuerysms as a sign of the transmural inflammation, IFN-gamma, IP- 10 and mig chemikines are correlated with vascular remodeling and expansion of aneurysms [20]. Smooth muscle cells can exert a tiggr function in the development of inflammatory processes involved in transmural inflammation by increased secretion of GM-CSF [21-23]. The bulk of the extracellular matrix was destroyed, the triple helical structure of collagen fibers removed. In addition, some pronounced hypertrophy was present in collagen fibers. The basal lamina is a crucial component of mechanical and functional blood vessels, constituting a sensor of extracellular microenvironment for endothelial cells and pericytes. In segments of thoracic aortic aneurysms the collagen I, laminin alpha 2 chain and fibonectin amount decreased [24,25]. Consistently with the common macroscopic observation that ascending aorta dilatations tend to expand asymmetrically, with prevalent involvement of vessel convexity and relative loss of the concavity, collagen type IV is more evident in the concavity and transcin in the convexity [26]. However, we could not detect any differences in the destruction of the extracellular matrix in the convex or concave aortic arcus. The synthesis of other chains of collagen, discussed already in the degeneration of aortic and mitral valves is a sign of overloading of the collagen fibers as primary stimuli [27]. Toumpoulis et al. demonstrate that increased collagen alpha 1 (XI) and V collagen mRNA and protein levels are linearly correlated with the size of the aneurysm and provide a potential mechanism for generation and progression of aneurysmal enlargement [28]. The hypothesis of an increased conversion of the basement membrane by a variant of the synthesized collagen fibers is underlined by the demonstration of increased expression of metalloproteinases ADAM10, ADAM17, matrix metalloproteinases MMP-2 and 9 [29-32]. A similar finding with increased MMP-8 in acute thoracic aortic dissection was recently reported [33]. Surprisingly, we detecded in the examined aortic, endothelial defects in the form of craters which we have described in a similar form in the degeneration of aortic valves. The functional significance of this change is completely unknown. Finally, we have found in explanted degenerated aortic and mitral valves, similar morphological changes in the endothelium and the extracellular matrix, which could indicate at least partially similar etiology. Above all, a malformation of collagen fibers in the center moves etiology. In summary, in descending aortic aneurysms and acquired aortic valves degeneration, the inflammation of the extracellular matrix resulting from enormous flow changes seems to play a central role. The increased incidence of thoracic aortic aneuryms by bicuspid aortic valves could be the expression of this hypothesis. Thus, basal membrane trans-synthesis seems to play an important role not only in congenital TAA forms. Recent studies with visualization technology suggest a flow change caused by wall processes with enormous stress fields (34). Further studies initiated by us on patients with TAA will investigate the relation between collagen alterations and flow changes, thus shedding new light on the aetiology of TAA.

\section{Conclusion}

In this study of explanted segments of thoracic aorta, several morphological modifications of the endocardium and extracellular matrix were identified by scanning electron microscopy. The similarity of these changes with degeneration of aortic and mitral valves lead to the suggestion that similar pathophysiological changes such as a possible synthesis failure of collagen fibers may play an important etiologic role in the development of aneurysms of thoracic aorta.

\section{Conflict of Interest}

I hereby declare that there were no financial or other interests in the execution and evaluation of this work.

\section{References}

1. Majumdar R, Miller DV, Ballman KV, Unnikrishnan G, McKellar SH et al. (2007) Elevated expressions of osteopontin and tenascin $C$ in ascending aortic aneurysms are associated with trileaflet aortic valves as compared with bicuspid aortic valve sbicuspid aortic valves. Cardiovasc Pathol 16(3): 144-150.

2. Meng YH, Tian C, Liu L, Wang L, Chang Q, et al. (2014) Elevated expression of connective tissue growth factor, osteopontin and increased collagen content in human ascending thoracic aortic aneurysms. Vascular 22(1): 20-27.

3. Kim JH, Na CY, Kim HW, Du Kim Y, Kwon JB, et al. (2010) Integration of gene-expression profiles and pathway ananlysis in ascending thoracic aortic aneurysms. Ann Vasc Surg 24(4): 538-549.

4. Kimura N, Futamura K, Arakawa M, Okada N, Okamura FH, et al. (2017) Gene expression profiling of acute type A aortic dissection combined with in vitro assessment. Eur J Cardio-Thorac Surg 52(4): 810-817. 
5. Hasham SN, Guo DC, Milesicz DM (2002) Genetic basis of thoracic aortic aneurysms and dissections. Curr Opin Cardiol 17(6): 677-683.

6. Takeda N, Komuro I (2019) Genetic basis of hereditary thoracic aortic aneurysms and dissections. Journal of Cardiology 74(2): 136-143.

7. Erbel R, Aboyans V, Boileau C, Bossone E, Bartolomeo RD, et al. (2014) ESC Committee for Practice Guidelines (2014) Guideline of the European Society for Cardiology (ESC) for diagnosis and therapy of Aortic diseases. Eur Heart J 35(41): 2873-2926.

8. Tromp G, Kuivaniemi H, Hinterseher I, Carey DJ (2010) Novel genetic mechanims for aortic aneurysms. Curr Atheroscler Rep 12(4): 259-266.

9. Ostberg NP, Zafar MA, Ziganshin BA, Elefteriades JA (2020) The Genetics of Thoracic Aortic Aneurysms and Dissection: A Clinical Perspective Biomolecules 10(2): pp. 182.

10. Robinson PN, Arteaga-Solis E, Baldock C, Collod-Be`roud G, Booms P, et al. (2006) The molecular genetics of Marfan syndrome and related disorders. J Med Genet 43(10): 769-787.

11. El-Hamamsy I, Yacoub MH (2009) Cellular and molecular mechanims of tgoracic aortic aneurysms. Nat Rev Cardiol 6(12): 771-786.

12. Pinard A, Jones GT, Milewicz DM (2019) Genetics of Thoracic and Abdominal Aortic Diseases Aneurysms, Dissections, and Ruptures. Circulation Research 124(4): 588-606

13. Verstraeten A, Meester J, Peeters S, Mortier G, Loeys B, et al. (2020) Chondrodysplasias and Aneurysmal Thoracic Aortopathy: An Emerging Tale of Molecular Intersection. Trend in molecular medicine 26(8): 783795.

14. Vaughan CJ , Casey M, , He J, Veugelers M, Henderson K, et al. (2002) Basson identification of a Chromosome 11q23.2-q24 locus for familial aortic aneurysm disease, a genetically heterogeneous disorder. 103(20): 2469-2475.

15. Koenig SN, LaHaye S, Feller JD, Rowland P, Hor KN, et al. 2017 Notch1 haploinsufficiency causes ascending aortic aneurysms in mice. JCl Insight 2(21): e91353.

16. Keramati AR, Sadeghpour A, Farahani MM, Chandok G, Mani A, et al. (2010) The non-syndomic familial thoracic aortic aneurysms and dissections maps to 15q21 locus. BMC Med Genet 11: 143.

17. Marin EP, Moeckel G, Al-Lamki R, Bradley J, Yan Q, et al. (2010) Identification and Regulation of Reticulon 4B (Nogo-B) in Renal Tubular Epithelial Cells. Am J Pathol 177(6): 2765-2773.

18. Wälchli T, Pernet V, Weinmann O, Shiu IY, Guzik-Kornacka A, et al. (2013) Nogo-A is a negative regulator of CNS angiogenesis. Proc Natl Acad Sci 110(21): 1943-1952.

19. Wang X, Searle AK, Chen YC, Peter K (2017) P6268 Downregulation of vascular cell adhesion molecule-1 using targeted microbubbles for the delivery of microRNA-126: treatment and prevention of abdominal aortic aneurysm, Eur Heart J 38(1): ehx493.P6268.

20. Yan H, Hu Y, Akk A, Ye K, Bacon J, et al. (2019) Interleukin-12 and -23 blockades mitigates elastase- induced abdominal aortic aneurysm. Pham Sci Rep 9: 10447
21. Ijaz T, Tilton RG, Brasier AR (2016) Cytokine amplification and macrophage effector functions in aortic inflammation and abdominal aortic aneurysm formation. J Thorac Dis 8(8): 746-754.

22. Takeda N, Hara H, Fujiwara T, Kanaya T, Maemura S, et al. (2018) TGF- $\beta$ Signaling-Related Genes and Thoracic Aortic Aneurysms and Dissections. Int J Mol Sci 19(7): 2125.

23. Hara H, Takeda N, Fujiwara T, Yagi H, Maemura S, et al. (2019) Activation of TGF- $\beta$ signaling in an aortic aneurysm in a patient with Loeys-Dietz syndrome caused by a novel loss-of-function variant of TGFBR1. Hum Genome Var 6(6).

24. Gurung R, Choong AM, Woo CC, Foo R, Sorokin V, et al. (2020) Genetic and Epigenetic Mechanisms Underlying Vascular Smooth Muscle Cell Phenotypic Modulation in Abdominal Aortic Aneurysm. Int J Mol Sci 21(17): 6334 .

25. Harman JL, Dobnikar L, Chappell J, Stokell BG, Dalby A, et al. (2019) Epigenetic regulation of vascular smooth muscle cells by histone $\mathrm{H} 3$ lysine 9 dimethylation attenuates target gene-induction by inflammatory signaling. Arterioscl Throm Vas 39(11): 2289-2302.

26. Liu P, Song Y, Zhou Y, Liu Y, Qiu T, et al. (2018) Cyclic Mechanical Stretch Induced Smooth Muscle Cell Changes in Cerebral Aneurysm Progress by Reducing Collagen Type IV and Collagen Type VI Levels. Cell Physiol Biochem 45(3): 1051-1060.

27. Mirzaie M, Schultz M, Schwartz P, Coulibaly M, Schöndube F, et al. (2003) Evidence of woven bone formation in heart valve disease. Ann Thorac Cardiovasc Surg 9(3): 163-169

28. Toumpoulis IK, Oxford JT, Cowan DB, Anagnostopoulos CE, Rokas CK, et al. (2009) Differential expression of collagen V and XI alpha-1 in human ascending thoracic aortic aneurysms. Ann Thorac Surg 88(2): 506-513.

29. Jana S, Chute M, Hu M, Winkelaar G, Owen CA, et al. (2020) ADAM (a Disintegrin and Metalloproteinase) 15 Deficiency Exacerbates Ang II (Angiotensin II)-Induced Aortic Remodeling Leading to Abdominal Aortic Aneurysm. Arterioscler Thromb Vasc Biol 40(8): 1918-1934.

30. Geng L, Wang W, Chen Y, Cao J, Lu L, et al. (2010) Elevation of ADAM10, ADAM17, MMP-2 and MMP-9 expression with media degeneration features $\mathrm{CaCl} 2$-induced thoracic aortic aneurysm in a rat model. Exp Mol Pathol 89(1): 72-81.

31. Jiao T, Yao Y, Zhang B, Hao DC, Sun QF, et al. (2017) Role of MicroRNA103a Targeting ADAM10 in Abdominal Aortic Aneurysm. BioMed Res Int, 2017(3): 1-14.

32. Yang I, LeBlanc ME, Cano I, Saez-Torres KL, Saint-Geniez M, et al. (2020) ADAM10 and ADAM17 proteases mediate proinflammatory cytokineinduced and constitutive cleavage of endomucin from the endothelial surface. J Biol Chem 295(19): jbc.RA119.011192.

33. Klaus V, Tanios-Schmies F, Reeps C, Trenner M, Matevossian E, et al (2017) Association of Matrix Metalloproteinase Levels with Collagen Degradation in the Context of Abdominal Aortic Aneurysm. Eur J Vasc Endovasc Surg 53(4): 549-558.

34. Meuschke M, Köhler B, Preim U, Preim B, Lawonn K, et al. (2016) Semiautomatic Vortex Flow Classification in 4D PC-MRI Data of the Aorta. Computer Graphics Forum 35 (3). 
This work is licensed under Creative Commons Attribution 4.0 License

To Submit Your Article Click Here: Submit Article

DOI: 10.32474/ACR.2020.03.000159

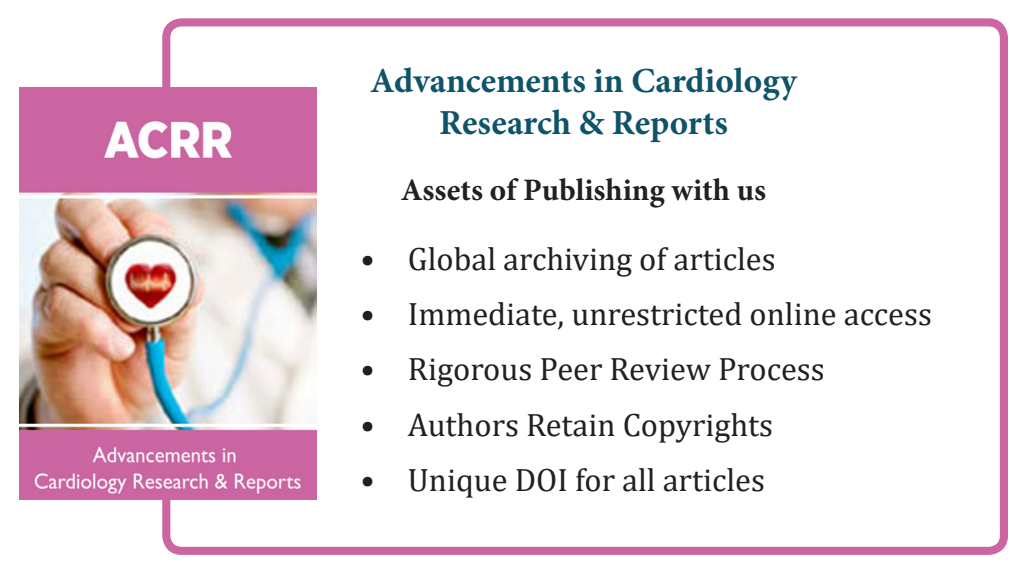

